\title{
MicroRNA signature of the human developing pancreas
}

\author{
Samuel Rosero ${ }^{1 \dagger}$, Valia Bravo-Egana ${ }^{1 \dagger}$, Zhijie Jiang $^{2}$, Sawsan Khuri ${ }^{2,3}$, Nicholas Tsinoremas $^{2}$, Dagmar Klein ${ }^{1}$, \\ Eduardo Sabates ${ }^{1}$, Mayrin Correa-Medina', Camillo Ricordi', Juan Domínguez-Bendala', Juan Diez ${ }^{1}$, \\ Ricardo L Pastori ${ }^{1^{*}}$
}

\begin{abstract}
Background: MicroRNAs are non-coding RNAs that regulate gene expression including differentiation and development by either inhibiting translation or inducing target degradation. The aim of this study is to determine the microRNA expression signature during human pancreatic development and to identify potential microRNA gene targets calculating correlations between the signature microRNAs and their corresponding mRNA targets, predicted by bioinformatics, in genome-wide RNA microarray study.

Results: The microRNA signature of human fetal pancreatic samples 10-22 weeks of gestational age (wga), was obtained by PCR-based high throughput screening with Taqman Low Density Arrays. This method led to identification of 212 microRNAs. The microRNAs were classified in 3 groups: Group number I contains 4 microRNAs with the increasing profile; II, 35 microRNAs with decreasing profile and III with 173 microRNAs, which remain unchanged. We calculated Pearson correlations between the expression profile of microRNAs and target mRNAs, predicted by TargetScan 5.1 and miRBase altgorithms, using genome-wide mRNA expression data. Group I correlated with the decreasing expression of 142 target mRNAs and Group II with the increasing expression of 876 target mRNAs. Most microRNAs correlate with multiple targets, just as mRNAs are targeted by multiple microRNAs. Among the identified targets are the genes and transcription factors known to play an essential role in pancreatic development.

Conclusions: We have determined specific groups of microRNAs in human fetal pancreas that change the degree of their expression throughout the development. A negative correlative analysis suggests an intertwined network of microRNAs and mRNAs collaborating with each other. This study provides information leading to potential twoway level of combinatorial control regulating gene expression through microRNAs targeting multiple mRNAs and, conversely, target mRNAs regulated in parallel by other microRNAs as well. This study may further the understanding of gene expression regulation in the human developing pancreas.
\end{abstract}

\section{Background}

MicroRNAs are small non-coding RNAs [1-3] that act mostly as translational repressors through binding to partially complementary sequences of target messenger RNAs. Recent studies indicate that in some cases microRNAs might act also as positive regulators of translation and transcription $[4,5]$. To date, more than 700 human microRNAs are annotated in the Wellcome Trust

\footnotetext{
* Correspondence: rpastori@med.miami.edu

+ Contributed equally

'Diabetes Research Institute, University of Miami, Miller School of Medicine, Miami FL, 33136, USA

Full list of author information is available at the end of the article
}

Sanger Institute microRNA database [6]. MicroRNAs play a fundamental role in regulation of gene expression, consequently affecting key biological events such as embryogenesis, stem cell proliferation/differentiation and organ development [7]. The method of conditional knockout of the microRNA-processing enzyme Dicer has been used to study the action of microRNAs in specific tissues and organs. This approach has confirmed that the expression of microRNAs is essential for morphogenesis of several systems, including the lungs, limbs, muscle, skin and neuronal development and differentiation [8-12] including the genesis of pancreatic islet cells [13]. Dicer-null animals displayed gross defects
C Biomed Central 
in all pancreatic lineages; the most dramatic reduction was seen in the endocrine cells, especially the insulinproducing beta cells. Another approach utilized to assess the role of microRNAs in organs/tissues is the loss of function, i.e., silencing or knock out of a single or cluster microRNAs. For instance, genetic deletion of the miR-1/miR-133 cluster, showed its crucial role in cardiac skeletal muscle development [14]. Several microRNAs have been described in the context of pancreatic development, pancreatic exocrine/endocrine microRNA expression or islet biology/physiology. For example, knockdown of miR-375, an islet microRNA that negatively controls insulin secretion [15], has a deleterious effect on the developing pancreas of zebra fish [16]. Mice lacking miR-375 (375KO) are hyperglycemic and exhibit an increase in total pancreatic alpha-cell numbers, whereas the pancreatic beta-cell mass is decreased [17]. Recent studies indicate that during human pancreatic development miR-7, miR-9, miR-375 and miR376 are specific islet microRNAs expressed at high levels $[18,19]$. MiR-124a is known to target FOXA2 the transcription factor crucial for early pancreatic formation [20] by affecting genes such as PDX1, KCNJ11 (Kir6.2) and SUR1, essential for the normal development of the pancreas, glucose metabolism and insulin secretion [21], while miR-15a, $-15 b,-16$ and -195 have important roles in regulating translation of NGN3, a transcription factor affecting the adoption of an endocrine fate during embryogenesis [22].

Research conducted over the last decade has outlined rather comprehensive "roadmap" of the major molecular events that shape mouse islet development $[23,24]$. Development of the human endocrine pancreas has not been studied as well as that of the mouse. The previous work has described expression of endocrine hormones as well as transcription factors, and presented morphological examination of islet formation during human fetal pancreatic development [25-29].

In this study we investigated the global expression profile of microRNAs in the human fetal pancreas from age 10 to 22 weeks of gestational age (wga) and found 212 microRNAs expressed throughout this entire period. Understanding the complex processes behind pancreatic development will require the identification of RNA targets that are controlled by the extensive microRNA network expressed throughout the process. To identify potential microRNA gene targets, we calculated the correlations between the expression profile of these 212 microRNAs and their corresponding mRNA targets, predicted by bioinformatic tools, that were found in the genome-wide RNA microarray study by Sarkar et al. [28]. These studies will advance our understanding of pancreatic development, potentially unveiling prospective therapeutic targets to treat diabetes.

\section{Results and discussion MicroRNA Expression profile during pancreatic development}

Using TaqMan Low Density Arrays (TLDA) from Applied Biosystems we have performed microRNA arrays with 10 samples acquired at different stages of human fetal pancreatic development. Specifically; 10 wga (two samples), 11 wga (one sample), 13 wga(one sample), 14 wga (three samples), 15 wga (one sample), 21 wga (one sample), 22 wga (one sample). The TLDA platform has been selected because it requires smaller amounts of RNA 100 ng per experiment, which is about $\sim 20$ times less than what is required for other microarray hybridization platforms, furthermore it delivers quantitative output. We identified 212 microRNAs expressed throughout all studied gestational ages. Interestingly several microRNAs reported previously in studies of mouse pancreatic development/regeneration and islet function were also found expressed during human pancreatic development (Table 1).

For the correlation analysis we arranged the samples in 3 gestational periods: $10-11$ wga (three samples); $13-15$ wga (five samples) and 21-22 wga (two samples) and classified the microRNAs in three groups according to their expression profile (Material and Methods). Groups I and II contain 4 and 35 microRNAs respectively. Their statistically significant $(\mathrm{p}<0.05)$ expression change was either up-regulated (group I) or down-regulated (group II) at least from one gestational stage to the other. Group III comprises of 173 microRNAs with expression relatively unchanged ( $p>0.05$ ) (Table 2 \& Additional file 1, Table S1). Table 2 was prepared using relative quantification (RQ) values normalized by nucleolar RNA (RNU48) as endogenous control (Additional file 1, Table S1). RQ is a measure of the abundance of microRNA transcripts at each developmental stage. The microRNAs in Table 2 are arranged according to their descending RQ starting at the stage 10 wga. MiR-7, miR-124, miR-9 and miR375 , are microRNAs previously reported as related to pancreatic islets [18-20]. We found that only statistically significant increase of expression was for miR-7. miR-375 showed an increasing trend, however slightly below the threshold value $(\mathrm{p}=0.08)$, which might be the result of a low sample number. Additional file 2, Table S2 shows the average RQs for microRNAs in group I and II in each gestational period.

A hierarchical cluster representation of microRNAs clearly shows the pattern of expression of these three groups (Figure. 1). 


\begin{tabular}{|c|c|}
\hline miR-7 & Expressed in pancreatic adult and fetal endocrine cells $[18,19,30]$. \\
\hline miR-375 & $\begin{array}{l}\text { Negative regulator of glucose-induced insulin secretion through myothrophin regulation [15]. miR-375 K/O mice are } \\
\text { hyperglycemic -more alpha cells; less beta-cells- [17]. Regulation of PI3 pathway by regulation of PDK1 in insulinoma } \\
\text { cells [31]. The miR-375 gene promoter directs expression selectively to endocrine pancreas [32]. }\end{array}$ \\
\hline miR-9 & $\begin{array}{l}\text { Expressed at high levels during islet development [19]. Target of transcription factor Onecut-2 impairing glucose- } \\
\text { induced insulin secretion in insulinoma cells. }\end{array}$ \\
\hline $\begin{array}{l}\text { miR-195; miR-16 miR-15a; } \\
\text { miR-15b }\end{array}$ & Role in pancreatic regeneration, possibly by targeting Ngn3 [22]. \\
\hline miR-124a & Regulation of insulin secretion machinery and transcription factor Foxa2 in insulinoma cells $[21,33]$. \\
\hline miR-218 & $\begin{array}{l}\text { Expressed in mouse early fetal pancreas, controls the liver and pancreatic development regulator Onecut-2 in liver } \\
\text { embryonic cells [34]. }\end{array}$ \\
\hline miR-484; miR-107; miR-30d & High glucose down-regulates their expression in insulinoma cells [35]. \\
\hline miR-146a & $\begin{array}{l}\text { Increased expression in islets from db/db obese mice, contributes to fatty acids-induced beta-cell dysfunction [36]. Pro- } \\
\text { inflammatory cytokines induce its expression in human islet and MIN6 cells [37]. }\end{array}$ \\
\hline miR-29a & Over-expression induced insulin resistance in 3 T3 adipocytes [38]. \\
\hline miR-503 & miR-503 is expressed in a pattern similar to that of miR-375 in a mouse progenitor cells at e14.5 pancreas [13]. \\
\hline miR-376a & Expressed at high levels during islet development [19]. \\
\hline miR-21; miR-34a & $\begin{array}{l}\text { Pro-inflammatory cytokines induce its expression in human islet and MIN6 cells [37]. miR-34a also contributes to fatty } \\
\text { acids-induced beta-cell dysfunction [36]. }\end{array}$ \\
\hline miR-96 & Increases mRNA and protein levels of granulophilin, a negative regulator of insulin exocytosis [33]. \\
\hline
\end{tabular}

These microRNAs have been previously described as expressed in adult or developing pancreatic tissue and/or having a functional role in islets/insulinoma cells.

\section{Inverse correlation between microRNA and mRNA during} human pancreatic development

Although mechanistically, microRNAs inhibit mRNA translation, the expression of a given microRNA has also been associated with the downregulation of its target mRNA levels [30,31]. Therefore, to identify potential microRNA targets, we performed a statistical analysis looking for inverse correlations between the microRNAs in groups I and II (a total of 39 microRNAs) and the algorithm-predicted target genes that were found in a human pancreatic development genome-wide mRNA microarray gene expression study [28]. Predictive algorithms are a powerful tool to identify potential RNA targets [32]. The target RNAs were selected by two of the most commonly used computational microRNA predictive target programs, miRBase [33] and TargetScan $[30,34]$. There is a limitation to this kind of analysis because it utilizes only the sequence correlation of 3'UTR mRNA domain with microRNA seed sequences. This excludes naturally occurring microRNA targets with recognition motifs within the gene coding sequence. This kind of microRNA/mRNA interaction has been recently reported as well [35]. Computational predictions often generate long lists of target genes and these are not always concordant [32]. Therefore, the correlations were calculated with target genes predicted by each program individually, and also by the intersection of both algorithms, as this might increase the odds of identifying the bona fide RNA targets [36].

High confidence correlation $\left(R^{2} \geq 0.8\right)$ analysis between microRNAs and gene targets identified 2832 and 9448 correlations using miRBase and TargetScan respectively
(Additional file 3, Table S3 and Additional file 4, Table S4). A total of 1018 genes were identified as potential targets by both predictive algorithms (Additional file 5, Table S5); microRNAs from group I correlated with decreased expression of 142 potential targets while micoRNAs from group II, correlated with the increasing expression of 876 potential targets (Table 3 ). For all microRNA groups the number of targets predicted by TargetScan was higher than by miRBase, which is in agreement with previous observations [37,38].

\section{Genes involved in pancreatic development correlated with microRNAs}

We searched for microRNAs that negatively correlated with genes from signaling pathways and transcription factors that are known to be involved in murine pancreatic development and/or regulate beta-cell development [39] (Table 4). Out of the 28 candidate genes, 11 were identified as potential targets for microRNAs. Most of the correlations corresponded to microRNAs from group II. Ten genes up-regulated throughout the development correlated with 19 decreasing microRNAs from group II. Decreasing gene SOX4, was identified as a potential target for miR-489 from group I. The identification of 19 microRNAs with decreasing expression along the pancreatic development, thus contributing to the upregulation of their potential targets, suggests a collaborative network of microRNAs and mRNAs during this period (Figure. 2). Most microRNAs target more than one gene and conversely a given mRNA could be the target of several microRNAs. For example, NEUROD1, a key transcription factor involved in the 
Table 2 MicroRNA groups classified according to their expression profiles

\begin{tabular}{|c|c|c|c|c|c|c|}
\hline Group I (4) & Group II (35) & Group III (173) & & & & \\
\hline miR-7 & miR-92 & miR-26a & miR-410 & let-7g & $\operatorname{miR}-142-5 p$ & miR-326 \\
\hline miR-141 & miR-214 & miR-19b & miR-200b & miR-148b & miR-615 & miR-488 \\
\hline miR-98 & miR-484 & miR-126 & miR-433 & let-7a & miR-486 & miR-629 \\
\hline \multirow[t]{32}{*}{ miR-489 } & miR-125a & miR-125b & miR-142-3p & miR-532 & miR-143 & miR-369-3p \\
\hline & miR-335 & miR-30c & miR-186 & miR-379 & miR-656 & miR-496 \\
\hline & miR-218 & miR-16 & miR-140 & miR-565 & miR-95 & miR-133a \\
\hline & miR-99b & miR-24 & miR-152 & miR-20b & miR-490 & miR-203 \\
\hline & miR-342 & miR-200c & miR-411 & miR-32 & miR-101 & miR-378 \\
\hline & miR-382 & miR-199a & miR-365 & miR-424 & miR-107 & miR-511 \\
\hline & miR-301 & miR-100 & miR-374 & miR-425-5p & miR-193a & miR-520g \\
\hline & miR-432 & miR-99a & miR-324-3p & miR-361 & miR-383 & miR-17-3p \\
\hline & miR-181b & miR-26b & miR-27b & miR-572 & miR-193b & miR-190 \\
\hline & miR-323 & miR-594 & miR-10a & miR-30e-5p & miR-339 & miR-450 \\
\hline & miR-103 & miR-127 & miR-320 & miR-423 & let-7e & miR-518b \\
\hline & miR-21 & miR-20a & miR-134 & miR-10b & let-7d & miR-659 \\
\hline & miR-130b & miR-130a & miR-429 & miR-183 & miR-372 & miR-376b \\
\hline & miR-135b & miR-30b & miR-137 & miR-146a & miR-213 & miR-338 \\
\hline & miR-182 & miR-30a-5p & miR-149 & miR-132 & miR-491 & miR-504 \\
\hline & miR-181d & miR-148a & miR-324-5p & miR-195 & miR-503 & miR-576 \\
\hline & miR-25 & miR-485-3p & miR-145 & miR-451 & miR-224 & miR-545 \\
\hline & miR-17-5p & miR-30d & miR-151 & miR-485-5p & miR-500 & miR-219 \\
\hline & miR-296 & miR-200a & miR-210 & miR-199b & miR-493 & miR-518e \\
\hline & miR-135a & miR-19a & miR-204 & miR-23a & miR-215 & miR-642 \\
\hline & miR-345 & miR-223 & miR-660 & miR-194 & miR-425 & miR-196b \\
\hline & miR-299-5p & miR-106b & miR-328 & miR-15a & miR-1 & miR-422a \\
\hline & miR-18a & miR-331 & miR-146b & miR-181c & miR-502 & miR-518c \\
\hline & miR-369-5p & miR-375 & miR-192 & let-7f & miR-206 & miR-337 \\
\hline & miR-519d & miR-197 & miR-221 & miR-340 & miR-650 & miR-189 \\
\hline & miR-494 & miR-191 & let-7c & miR-362 & miR-29c & miR-509 \\
\hline & miR-550 & miR-93 & miR-30e-3p & miR-22 & miR-124a & miR-299-3p \\
\hline & miR-187 & miR-27a & miR-9 & miR-654 & miR-452 & miR-381 \\
\hline & miR-409-5p & miR-376a & miR-30a-3p & miR-330 & miR-133b & miR-329 \\
\hline & miR-380-5p & miR-487b & miR-31 & miR-155 & miR-139 & miR-518f \\
\hline & miR-512-3p & miR-15b & miR-28 & miR-501 & miR-29a & \\
\hline & miR-96 & miR-222 & miR-23b & hsa-let-7b & miR-542-5p & \\
\hline
\end{tabular}

MicroRNAs from group I and II increase and decrease their expressions respectively throughout the entire studied period. Group III includes microRNAs with relatively constant expression throughout the period studied.

conversion of pancreatic progenitor cells into endocrine cells [40] was identified as a potential target of five microRNAs: miR-17-5p, miR-18a, miR-92, miR-103 and miR-494. The decrease in the expression of these five microRNAs would lead to the up-regulation of NEUROD1. It is apparent that microRNAs can target genes/ transcription factors that have a role at different stages of embryogenesis, for example miR-342 targets genes such as GATA-4, involved in the formation of definitive endoderm [41] and transcription factors FOXA2 and MAFB both involved in beta-cell differentiation and maturation $[39,42]$.

\section{Conclusions}

In this study we determined the microRNA expression signature during human pancreatic development, identifying a total of 212 microRNAs expressed at least once in one of the four stages evaluated (10 to $22 \mathrm{wga}$ ). To further our understanding of gene expression regulation in the human developing pancreas, we compared this microRNA signature with the global expression of genes during the similar period of the developing pancreas. There are potential limitations to this kind of study that should be considered: 1 ) the study was designed under the assumption that microRNAs are associated with 


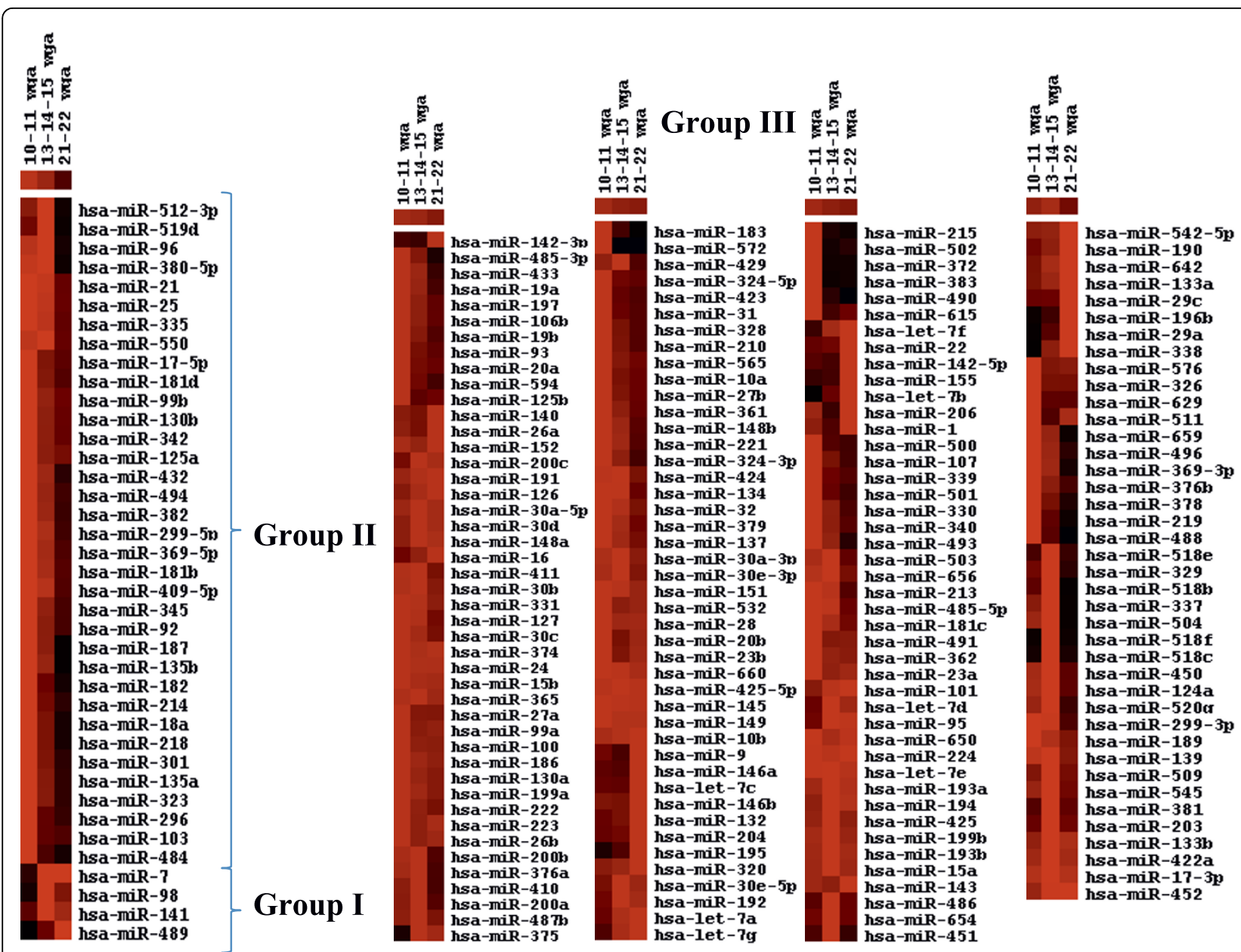

Figure 1 Expression of microRNAs during human pancreatic development. The Heat- map figures were obtained using Cluster and Treeview software [44] with the data presented in Additional file 1, Table S1. This table shows correlation among expression profiles of microRNAs comprised into three groups from all studied fetal pancreatic samples; Group I, Group II and Group III. The color of each cell represents the expression of microRNA normalized to small nucleolar RNU48 RNA. Colorgram depicts intensity of expression from high (bright red) to low (black). Please note that even though in some cases the group III colorgram suggests a change of expression throughout the gestational stages (e.g miR-376, miR-378, etc), these were found to be not statistically significant.

downregulation of their targets. However, some microRNAs were reported as positive regulators of transcription or translation $[4,5], 2)$ the correlation between microRNAs and gene expression was performed with mRNAs only, but there are some microRNAs that regulate only protein translation; 3) all potential targets were identified by algorithms analyzing the 3'UTR of the mRNA, while some microRNAs can also interact with targets containing the recognition sequence in the coding region; 4) the expression of microRNAs and mRNAs was evaluated on different set of sample tissues, using different platforms by different laboratories; 5) in this study we have analyzed the pancreas as a whole, instead of looking at the cellular subsets. Therefore, it is not possible to determine if the observed changes corresponded to a specific cell population (e.g endocrine progenitors, mesenchymal tissue etc).

Despite of these caveats, the correlation between the expression of hundreds of microRNAs with the analysis of thousands of genes expressed during human pancreatic development suggests the intertwined collaborative network of microRNAs and mRNAs. It also provides broad and useful information to explore potential two-way level of gene expression control regulation in which microRNAs target multiple mRNAs, and, target mRNAs are regulated in parallel by multiple microRNAs. Ultimately, the speculation regarding the roles of all these presumptive targets will be justified only if they are experimentally validated. 
Table 3 Correlation between microRNAs and gene targets

\begin{tabular}{|c|c|c|c|c|c|c|c|c|}
\hline \multirow[b]{2}{*}{ miRNA } & \multicolumn{4}{|c|}{ Genes Group I } & \multirow[b]{2}{*}{ miRNA } & \multicolumn{3}{|c|}{ Genes Group II } \\
\hline & TargetScan & Sanger & & Shared & & TargetScan & Sanger & Shared \\
\hline miR-141 & 318 & 99 & & 53 & miR-17-5p & 433 & 121 & 65 \\
\hline miR-7 & 463 & 152 & & 43 & miR-181d & 349 & 114 & 55 \\
\hline miR-489 & 209 & 95 & & 34 & miR-296 & 382 & 97 & 53 \\
\hline \multirow[t]{32}{*}{ miR-98 } & 105 & 55 & & 12 & miR-214 & 513 & 92 & 48 \\
\hline & & & & & miR-103 & 384 & 115 & 46 \\
\hline & & & & & miR-181b & 284 & 88 & 46 \\
\hline & & & & & miR-125a & 385 & 100 & 45 \\
\hline & & & & & miR-484 & 455 & 82 & 40 \\
\hline & & & & & miR-345 & 263 & 71 & 34 \\
\hline & & & & & miR-301 & 215 & 69 & 28 \\
\hline & & & & & miR-182 & 291 & 77 & 27 \\
\hline & & & & & miR-18a & 231 & 98 & 27 \\
\hline & & & & & miR-218 & 248 & 89 & 27 \\
\hline & & & & & miR-342 & 417 & 72 & 24 \\
\hline & & & & & miR-130b & 221 & 92 & 23 \\
\hline & & & & & miR-135a & 231 & 74 & 23 \\
\hline & & & & & miR-323 & 274 & 67 & 22 \\
\hline & & & & & miR-494 & 385 & 47 & 22 \\
\hline & & & & & miR-382 & 193 & 58 & 21 \\
\hline & & & & & miR-432 & 241 & 60 & 21 \\
\hline & & & & & miR-135b & 190 & 59 & 19 \\
\hline & & & & & miR-25 & 151 & 46 & 17 \\
\hline & & & & & miR-92 & 200 & 67 & 17 \\
\hline & & & & & miR-21 & 106 & 56 & 15 \\
\hline & & & & & miR-299-5p & 162 & 64 & 15 \\
\hline & & & & & miR-335 & 220 & 45 & 14 \\
\hline & & & & & miR-187 & 60 & 71 & 12 \\
\hline & & & & & miR-512-3p & 120 & 19 & 12 \\
\hline & & & & & miR-519d & 139 & 28 & 11 \\
\hline & & & & & miR-550 & 150 & 31 & 11 \\
\hline & & & & & miR-96 & 124 & 47 & 11 \\
\hline & & & & & miR-409-5p & 85 & 55 & 10 \\
\hline & & & & & miR-99b & 32 & 76 & 7 \\
\hline & & & & & miR-380-5p & 200 & 30 & 6 \\
\hline & & & & & miR-369-5p & 19 & 54 & 2 \\
\hline Total & 1095 & 401 & 142 & & Total & 8353 & 2431 & 876 \\
\hline
\end{tabular}

Data for this table was obtained setting inverse correlations with $\mathrm{R}^{2}>=0.80$ as a cut off high confidence level.

\section{Methods}

\section{Human fetal pancreas procurement}

Human fetal pancreases from 10 to 22 weeks of gestational age (wga) were collected from fetal tissue immediately after elective termination of pregnancy. The healthy women admitted to local clinics were properly informed and gave their consent to use fetal tissues for research studies. The study is in compliance with US legislation and the guidelines of the University of Miami. Gestational age was determined on the basis of the last menstrual period, with ultrasonographic measurements of the Crown-Rump Length, and the biparietal diameter.

\section{MicroRNA isolation}

MicroRNA isolation was performed using mirVana microRNA Isolation kit from Ambion/Applied Biosystems (Foster City CA), following protocol for the total RNA isolation procedure provided by the manufacturer.

\section{Quantitative microRNA profiling: criteria for inclusion of} microRNAs in this study

We performed this study with 10 human fetal pancreases of following gestational stages: two samples (10 wga); one sample (11 wga); one sample (13 wga); three samples (14 wga); one sample (15 wga); one sample (21 wga) and one 
Table 4 Genes involved in pancreatic development correlated with microRNAs

\begin{tabular}{|c|c|c|}
\hline Transcription factors & Sanger & TargetScan \\
\hline$|s| 1$ & miR-182 (II) & miR-382 (II), miR-432 (II) \\
\hline HIxb9 & 0 & 0 \\
\hline Hex & 0 & 0 \\
\hline Prox1 & miR-181b (II), miR-181 d (II) & miR-125a (II), miR-218 (II) \\
\hline $\operatorname{Hnf} 1 \beta$ & 0 & 0 \\
\hline Hnf6 & 0 & 0 \\
\hline Ptf1a & 0 & 0 \\
\hline$P d x 1$ & 0 & 0 \\
\hline $\mathrm{Pbx} 1$ & 0 & 0 \\
\hline Sox9 & 0 & miR-130b (II), miR-301 (II), miR-494 (II) \\
\hline Sox4 & 0 & $\operatorname{miR}-489(\mathrm{I})$ \\
\hline GATA-4 & 0 & miR-187 (II), miR-214 (II), miR-342 (II) \\
\hline GATA-6 & 0 & 0 \\
\hline Ngn3 & 0 & 0 \\
\hline NeuroD1 & 0 & miR-17-5p (II), miR-18a (II), miR-92 (II), miR-103 (II), miR-494 (II) \\
\hline Insm1 & miR-99b (II) & miR-99b (II), miR-345 (II), miR-494 (II) \\
\hline Myt1 & 0 & 0 \\
\hline Pax6 & miR-187 (II) & miR-130b (II), miR-301 (II) \\
\hline Pax4 & 0 & 0 \\
\hline $\mathrm{Nk} \times 2.2$ & miR-182 (II) & 0 \\
\hline Nkx6.1 & 0 & 0 \\
\hline MafA & 0 & 0 \\
\hline MafB & 0 & miR-181 d (II), miR-342 (II) \\
\hline Foxa1 & 0 & 0 \\
\hline Foxa2 & 0 & miR-342 (II) \\
\hline HNF1 $\alpha$ & 0 & 0 \\
\hline $\mathrm{HNF} 4 \alpha$ & 0 & 0 \\
\hline TCF7L2 & 0 & 0 \\
\hline
\end{tabular}

Data for this table was obtained setting inverse correlations with $\mathrm{R}^{2}>=0.8$ as a cut off high confidence level. Numbers in parenthesis indicates the microRNA group.

sample (22 wga). Total RNA was isolated using mirVana microRNA Isolation kit, cDNA synthesis and the PCR amplification was performed according to the manufacturer's instructions (Applied Biosystems, Foster City, CA). MicroRNA profiling was performed with micro fluidic cards TaqMan ${ }^{\circledR}$ Low Density Array (TLDA, v1.0) for human microRNAs, which allows quantitative assessment of 352 microRNAs using the AB7900 instrument (Applied Biosystems). Quantitative values were calculated as relative quantification (RQ), normalized to endogenous control small nucleolar RNA RNU48, which is expressed evenly in all samples. RQs were calculated with SDS software supplied by the manufacturer (Applied Biosystems), utilizing the equation $R Q=2^{-\Delta C t}$ [43], where $\mathrm{Ct}$ is the number of cycles at which the sample reaches a software-determined threshold within the exponential amplification phase. $\mathrm{Ct} \geq 35$ cycles was considered as undetermined. The Gene Expression Omnibus (GEO) accession number is GSE22026.
For the correlation analysis we arranged the samples in 3 gestational periods: $10-11$ wga; $13-15$ wga and 2122 wga. Only microRNAs that amplified in 2 out 3 samples for 10-11 wga period, 4 out of 5 samples for 13-15 wga and 2 out of 2 samples in 21-22 wga were considered as positively expressed. Statistical analysis between the groups: $10-11$ wga vs $13-15$ wga; $10-11$ wga vs $21-22$ wga and 13-15 wga vs 21-22 wga was performed with two-tailed Student's t test (Additional file 1, Table S1). Values were considered significant when $\mathrm{p}<0.05$. The microRNAs were classified according to their expression profile into three groups. Group I contained microRNAs with the expression increased at least from one gestational stage to the other $(\mathrm{p}<0.05)$. Group II contained microRNAs with the expression decreased at least from one gestational stage to the other $(\mathrm{p}<0.05)$. In group III we included the microRNAs with the expression unchanged throughout the studied gestational stages ( $\mathrm{p}>0.05)$. 




\section{MicroRNA target gene databases}

Two microRNA target databases were used in this analysis. One arch.v5.txt.homo_sapiens.zip, downloaded from Sanger miRBase Targets http://microrna.sanger.ac. uk/cgi-bin/targets/v5/download.pl; the other Nonconserved_Site_Context_Scores.zip, downloaded from TargetScan http://www.targetscan.org/cgi-bin/targetscan/ data_download.cgi?db=vert_50.

\section{Correlation Analysis}

mRNA gene expression files were retrieved from Sarkar SA, Kobberup S, Wong R, Lopez AD, Quayum N, Still T, Kutchma A, Jensen JN, Gianani R, Beattie GM et al: Global gene expression profiling and histochemical analysis of the developing human fetal pancreas [28]. 22,000 genes were measured by 54,675 probe-sets on Human Genome HG U133 Plus 2.0 microarrays (Affymetrix, Santa Clara, CA, USA). The mRNA hybridization data from genes with multiple probes were averaged prior to the correlation analysis. For the correlation analysis the Sarkar et al gene expression data were grouped in three periods: 9, 10 and 11 wga (9-11); 15 wga; and 20, 23 wga. The gene expression of these three periods was compared to the microRNA expression corresponding to the three following periods: 10-11 wga; 13-15 wga and 21-22 wga. The Pearson correlation of the expression profile between microRNA and a target gene was calculated in the $\mathrm{R}$ package. The correlation coefficient $(\mathrm{r})$ was calculated to determine the regulatory role of the microRNA on its target genes. The correlation with $r$ close to -1 depicts a strong negative correlation between microRNA and its target gene, indicating the suppression function of microRNA on its target gene. $P$-value is used to test $\mathrm{H}^{0}: \mathrm{r}=0$. Benjamini-Hochberg FDR was used to correct the original $\mathrm{p}$-value for multiple test correction. The correlations with adjusted $p$-value $<0.05$ are significant 
correlations, and among these correlations the ones with $\left(R^{2} \geq 0.8\right)$ are significantly negative correlations where microRNAs suppress the expression of target genes in terms of expression in the three gestational ages.

\section{Abbreviations of genes referenced in this study}

Isl1: Insulin gene enhancer protein; Hlxb9: homeo box HB9; Hex (Hhex):hematopoietically expressed homeobox protein; Prox1: Homeobox prospero-like protein; HNF1 $\beta$ : hepatocyte nuclear factor 1 homeobox B; HNF6: hepatocyte nuclear factor 6; Ptf1a: Pancreas specific transcription factor, 1a; Pdx1: Pancreatic and duodenal homeobox 1; Pbx1: Pre-B-cell leukemia transcription factor 1; Sox9: transcription factor sox9; Sox4:transcription factor sox4; GATA-4: transcription factor gata-4; GATA6: transcription factor gata-6; Ngn3: neurogenin-3; NeuroD1: Neurogenic differentiation 1; Insm1: Insulinoma-associated protein 1; Myt1: Myelin transcription factor 1; Pax6: Paired box gene 6: Pax4: Paired box gene 4; Nkx2.2: Homeobox protein Nkx-2.2; Nkx6.1: Homeobox protein Nkx-6.1; MafA: V-maf musculoaponeurotic fibrosarcoma oncogene homolog a (avian); MafB: V-maf musculoaponeurotic fibrosarcoma oncogene homolog b (avian); Foxa1: forkhead box A1; Foxa2: forkhead box A2; HNF1 $\alpha$ : hepatocyte nuclear factor 1 homeobox A; HNF4 $\alpha$ : Hepatocyte nuclear factor 4 alpha; TCF7L2: Transcription factor 7-like 2 (T-cell specific, HMG-box); kir6.2: ATP-sensitive $\mathrm{K}+$ channel; sur1: sulfonylurea receptor 1 .

\section{Additional material}

Additional file 1: Table S1: MicroRNA PCR array data of human developing pancreas. PCR amplification cycles (CTs) were used to calculate RQs using small nucleolar RNU48 RNA as endogenous control. The $t$ test between the different stages was calculated with individual RQs.

Additional file 2: Table S2: Average RQ values for microRNAs included in group I \& II.

Additional file 3: Table S3: Correlation between microRNAs and gene targets predicted by miRBase algorithm.

Additional file 4: Table S4: Correlation between microRNAs and gene targets predicted by TargetScan algorithm.

Additional file 5: Table S5: Correlation between microRNAs and gene targets predicted by both algorithms, miRBase and TargetScan. In additional files 3, 4 and 5, the data for microRNAs are average RQs. Data for genes are hybridization intensity values from normalized arrays [28].

\section{Acknowledgements}

This work was supported by the Diabetes Research Institute Foundation, the Peacock Foundation and the Foundation for Diabetes Research.

Author details

'Diabetes Research Institute, University of Miami, Miller School of Medicine, Miami FL, 33136, USA. ${ }^{2}$ Center for Computational Science, University of Miami, Miami FL, 33136, USA. ${ }^{3}$ Dr. John T. Macdonald Foundation
Department of Human Genetics, University of Miami, Miller School of Medicine, Miami FL, 33136, USA.

\section{Authors' contributions}

VBE and SR performed research, analyzed data and wrote the manuscript. ZJ, SK and NT performed the computational analysis. ES contributed to the correlation statistical analysis. DK analyzed data and wrote the manuscript. MCM collected the samples. CR analyzed the data. JDB analyzed the data and wrote the manuscript. JD supervised the collection of samples, analyzed the data and reviewed the manuscript. RLP initiated and supervised the research, analyzed the data and wrote the manuscript. All the authors read and approved the final version of the manuscript.

\section{Competing interests}

The authors declare that they have no competing interests.

Received: 2 June 2010 Accepted: 22 September 2010

Published: 22 September 2010

\section{References}

1. Ambros V: microRNAs: tiny regulators with great potential. Cell 2001, 107(7):823-826.

2. Bartel DP: MicroRNAs: genomics, biogenesis, mechanism, and function. Cell 2004, 116(2):281-297.

3. Pasquinelli AE: MicroRNAs: deviants no longer. Trends Genet 2002, 18(4):171-173.

4. Place RF, Li LC, Pookot D, Noonan EJ, Dahiya R: MicroRNA-373 induces expression of genes with complementary promoter sequences. Proc Natl Acad Sci USA 2008, 105(5):1608-1613.

5. Vasudevan $S$, Tong $Y$, Steitz JA: Switching from repression to activation: microRNAs can up-regulate translation. Science 2007, 318(5858):1931-1934.

6. Griffiths-Jones S: The microRNA Registry. Nucleic Acids Res 2004, , 32 Database: D109-111.

7. Bernstein E, Kim SY, Carmell MA, Murchison EP, Alcorn H, Li MZ, Mills AA, Elledge SJ, Anderson KV, Hannon GJ: Dicer is essential for mouse development. Nat Genet 2003, 35(3):215-217.

8. Harfe BD, McManus MT, Mansfield JH, Hornstein E, Tabin CJ: The RNaselll enzyme Dicer is required for morphogenesis but not patterning of the vertebrate limb. Proc Natl Acad Sci USA 2005, 102(31):10898-10903.

9. Harris KS, Zhang Z, McManus MT, Harfe BD, Sun X: Dicer function is essential for lung epithelium morphogenesis. Proc Natl Acad Sci USA 2006, 103(7):2208-2213.

10. O'Rourke JR, Georges SA, Seay HR, Tapscott SJ, McManus MT, Goldhamer DJ, Swanson MS, Harfe BD: Essential role for Dicer during skeletal muscle development. Dev Biol 2007, 311(2):359-368.

11. Yi R, O'Carroll D, Pasolli HA, Zhang Z, Dietrich FS, Tarakhovsky A, Fuchs E: Morphogenesis in skin is governed by discrete sets of differentially expressed microRNAs. Nat Genet 2006, 38(3):356-362.

12. Kosik KS: The neuronal microRNA system. Nat Rev Neurosci 2006 7(12):911-920

13. Lynn FC, Skewes-Cox P, Kosaka Y, McManus MT, Harfe BD, German MS: MicroRNA expression is required for pancreatic islet cell genesis in the mouse. Diabetes 2007, 56(12):2938-2945.

14. Cordes KR, Srivastava D: MicroRNA regulation of cardiovascular development. Circ Res 2009, 104(6):724-732.

15. Poy MN, Eliasson L, Krutzfeldt J, Kuwajima S, Ma X, Macdonald PE, Pfeffer S, Tuschl T, Rajewsky N, Rorsman P, et al: A pancreatic islet-specific microRNA regulates insulin secretion. Nature 2004, 432(7014):226-230.

16. Kloosterman WP, Lagendijk AK, Ketting RF, Moulton JD, Plasterk RH: Targeted inhibition of miRNA maturation with morpholinos reveals a role for miR-375 in pancreatic islet development. PLoS Biol 2007, 5(8): e203.

17. Poy MN, Hausser J, Trajkovski M, Braun M, Collins S, Rorsman P, Zavolan M Stoffel M: miR-375 maintains normal pancreatic alpha- and beta-cell mass. Proc Natl Acad Sci USA 2009, 106(14):5813-5818.

18. Correa-Medina M, Bravo-Egana V, Rosero S, Ricordi C, Edlund H, Diez J, Pastori RL: MicroRNA miR-7 is preferentially expressed in endocrine cells of the developing and adult human pancreas. Gene Expr Patterns 2009, 9(4):193-199. 
19. Joglekar MV, Joglekar VM, Hardikar AA: Expression of islet-specific microRNAs during human pancreatic development. Gene Expr Patterns 2009, 9(2):109-113.

20. Friedman $\mathrm{JR}$, Kaestner $\mathrm{KH}$ : The Foxa family of transcription factors in development and metabolism. Cell Mol Life Sci 2006, 63(19-20):2317-2328.

21. Baroukh N, Ravier MA, Loder MK, Hill EV, Bounacer A, Scharfmann R, Rutter GA, Van Obberghen E: MicroRNA-124a regulates Foxa2 expression and intracellular signaling in pancreatic beta-cell lines. J Biol Chem 2007, 282(27):19575-19588.

22. Joglekar MV, Parekh VS, Mehta S, Bhonde RR, Hardikar AA: MicroRNA profiling of developing and regenerating pancreas reveal posttranscriptional regulation of neurogenin3. Dev Biol 2007, 311(2):603-612.

23. Edlund $\mathrm{H}$ : Factors controlling pancreatic cell differentiation and function. Diabetologia 2001, 44(9):1071-1079.

24. Edlund $\mathrm{H}$ : Pancreatic organogenesis-developmental mechanisms and implications for therapy. Nat Rev Genet 2002, 3(7):524-532.

25. Lyttle BM, Li J, Krishnamurthy M, Fellows F, Wheeler MB, Goodyer CG, Wang R: Transcription factor expression in the developing human fetal endocrine pancreas. Diabetologia 2008, 51(7):1169-1180.

26. Piper K, Brickwood S, Turnpenny LW, Cameron IT, Ball SG, Wilson DI, Hanley NA: Beta cell differentiation during early human pancreas development. J Endocrinol 2004, 181(1):11-23.

27. Polak M, Bouchareb-Banaei $L$, Scharfmann R, Czernichow P: Early pattern of differentiation in the human pancreas. Diabetes 2000, 49(2):225-232.

28. Sarkar SA, Kobberup S, Wong R, Lopez AD, Quayum N, Still T, Kutchma A, Jensen JN, Gianani R, Beattie GM, et al: Global gene expression profiling and histochemical analysis of the developing human fetal pancreas. Diabetologia 2008, 51(2):285-297.

29. Jeon J, Correa-Medina M, Ricordi C, Edlund H, Diez JA: Endocrine cell clustering during human pancreas development. J Histochem Cytochem 2009, 57(9):811-824.

30. Grimson A, Farh KK, Johnston WK, Garrett-Engele P, Lim LP, Bartel DP: MicroRNA targeting specificity in mammals: determinants beyond seed pairing. Mol Cell 2007, 27(1):91-105.

31. Lim LP, Lau NC, Garrett-Engele P, Grimson A, Schelter JM, Castle J, Bartel DP, Linsley PS, Johnson JM: Microarray analysis shows that some microRNAs downregulate large numbers of target mRNAs. Nature 2005, 433(7027):769-773.

32. Rajewsky N: microRNA target predictions in animals. Nat Genet 2006 38(Suppl):S8-13.

33. Griffiths-Jones S, Grocock RJ, van Dongen S, Bateman A, Enright AJ: miRBase: microRNA sequences, targets and gene nomenclature. Nucleic Acids Res 2006, 34 Database: D140-144.

34. Lewis BP, Burge CB, Bartel DP: Conserved seed pairing, often flanked by adenosines, indicates that thousands of human genes are microRNA targets. Cell 2005, 120(1):15-20

35. Tay Y, Zhang J, Thomson AM, Lim B, Rigoutsos I: MicroRNAs to Nanog, Oct4 and Sox 2 coding regions modulate embryonic stem cell differentiation. Nature 2008, 455(7216):1124-1128.

36. Zhou JLS, Melfi V, Verducci J: Composite microrna target predictions and comparisons of several prediction algorithms. Mathematical Biosciences Institute, The Ohio State University. Technical Report 512006.

37. Huang JC, Babak T, Corson TW, Chua G, Khan S, Gallie BL, Hughes TR, Blencowe BJ, Frey BJ, Morris QD: Using expression profiling data to identify human microRNA targets. Nat Methods 2007, 4(12):1045-1049.

38. Wang YP, Li KB: Correlation of expression profiles between microRNAs and mRNA targets using NCl-60 data. BMC Genomics 2009, 10:218.

39. Oliver-Krasinski JM, Stoffers DA: On the origin of the beta cell. Genes Dev 2008, 22(15):1998-2021.

40. Chu K, Nemoz-Gaillard E, Tsai MJ: BETA2 and pancreatic islet development. Recent Prog Horm Res 2001, 56:23-46.

41. Zhang $C$, Ye $X$, Zhang $H$, Ding $M$, Deng $H$ : GATA factors induce mouse embryonic stem cell differentiation toward extraembryonic endoderm. Stem Cells Dev 2007, 16(4):605-613.

42. Artner I, Blanchi B, Raum JC, Guo M, Kaneko T, Cordes S, Sieweke M, Stein R: MafB is required for islet beta cell maturation. Proc Natl Acad Sci USA 2007, 104(10):3853-3858.

43. Livak KJ, Schmittgen TD: Analysis of relative gene expression data using real-time quantitative PCR and the 2(-Delta Delta C(T)) Method. Methods 2001, 25(4):402-408
44. Eisen MB, Spellman PT, Brown PO, Botstein D: Cluster analysis and display of genome-wide expression patterns. Proc Natl Acad Sci USA 1998, 95(25):14863-14868

doi:10.1186/1471-2164-11-509

Cite this article as: Rosero et al:: MicroRNA signature of the human developing pancreas. BMC Genomics 2010 11:509.

\section{Submit your next manuscript to BioMed Central and take full advantage of:}

- Convenient online submission

- Thorough peer review

- No space constraints or color figure charges

- Immediate publication on acceptance

- Inclusion in PubMed, CAS, Scopus and Google Scholar

- Research which is freely available for redistribution

Submit your manuscript at www.biomedcentral.com/submit
C Biomed Central 